\title{
COMPOSIÇÃo QUÍMICA E DIGESTIBILIDADE DA PORNUNÇA SOB DUAS FONTES DE ADUBAÇÃO ORGÂNICA E CORTES ${ }^{1}$
}

\author{
FRANCISCO HUGO HERMÓGENES DE ALENCAR ${ }^{*}$, DIVAN SOARES DA SILVA3, \\ ALBERÍCIO PEREIRA DE ANDRADE ${ }^{4}$, MARIA SOCORRO DE SOUZA CARNEIRO ${ }^{5}$, JOSÉ VALMIR FEITOSA ${ }^{6}$
}

\begin{abstract}
RESUMO - O objetivo do presente trabalho foi avaliar o efeito da adubação orgânica e cortes sobre a composição química e a digestibilidade in vitro da fitomassa aérea da pornunça. Foi utilizado o delineamento experimental de blocos casualizados em parcelas subdivididas com quatro cortes, duas adubações e quatro repetições. Os cortes foram realizados nos meses de fevereiro, junho e outubro de 2011 e fevereiro de 2012 . A adubação foi com esterco bovino e ovino aplicados nos meses de maio de 2010 e março de 2011 na quantidade de $20 \mathrm{Mg}$ $\mathrm{ha}^{-1}$. Foram avaliados os componentes estruturais da parte aérea, tais como limbo foliar, pecíolo, ramo e completo (limbo foliar mais pecíolo e ramo) da pornunça. Os estercos bovino e ovino não influenciaram $(\mathrm{P}>0,05)$ a composição química dos componentes estruturais da parte aérea. Diferenças foram verificadas entre os cortes, exceto para a matéria seca (MS) do limbo foliar e do componente completo de extrato etéreo (EE), fibra em detergente neutro $($ FDN), fibra em detergente ácido (FDA) e hemicelulose $(\mathrm{HC})$. Houve efeito $(\mathrm{P}<0,05)$ para a digestibilidade in vitro da MS dos componentes estruturais nos diferentes cortes, sendo a maior digestibilidade para os componentes estruturais no corte realizado em fevereiro de 2011. Menores teores de proteína bruta foram encontrados nos componentes pecíolo e ramo. A pornunça deve ser considerada como alternativa alimentar para os animais em função dos valores da composição química apresentada neste estudo, sendo o limbo foliar a parte da planta que apresenta o melhor valor nutritivo.
\end{abstract}

Palavras-chave: Esterco. Forrageira nativa. Manihot sp. Semiárido.

\section{CHEMICAL COMPOSITION AND DIGESTIBILITY OF PORNUNÇA UNDER TWO SOURCES OF ORGANIC FERTILIZER}

\begin{abstract}
The objective of this Study was to evaluate the effect of organic fertilizer and cuts on the chemical composition and in vitro digestibility of the air pornunça biomass. The experimental design of randomized blocks in a split plot with four courts, two fertilization, and four replications. The cuts were made in February, June and October 2011 and February 2012. The fertilizer was with cattle and sheep manure, applied in May 2010 and March 2011 in the amount of $20 \mathrm{Mg} \mathrm{ha}^{-1}$. We evaluated the structural components of the shoot, such as leaf blade, petiole, branch and full (leaf blade and petiole more branch) of pornunça. The manure beef and lamb did not influence $(\mathrm{P}>0.05)$ the chemical composition of the structural components of the shoot. Differences were noted between the cuts, except for dry matter (DM) of the leaf blade and the full component of ether extract (EE), neutral detergent fiber (NDF), acid detergent fiber (ADF) and hemicellulose (HC). There was a significant $(\mathrm{P}<0.05)$ for the in vitro digestibility of the MS of the structural components in different cuts, with the highest digestibility for structural components in the cut made in February 2011. Lower crude protein was found in the petiole and components branch. The pornunça should be considered as an alternative food for animals according to the chemical composition of the values presented in this study, with the leaf surface of the plant part that presents the best nutritional value.
\end{abstract}

Keywords: Manure. Native forage. Manihot sp. Semiarid.

\footnotetext{
*Autor para correspondência

${ }^{1}$ Recebido para publicação em 07/03/2014; aceito em 06/05/2015.

Trabalho de Tese de Doutorado em Zootecnia do primeiro autor.

${ }^{2}$ Departamento de Ensino, IFCE, Campus Juazeiro do Norte, Av. Plácido Aderaldo Castelo, 1646 - Bairro Planalto Juazeiro do Norte (CE), Fone (88) 2101 5300, CEP: 63.040-540; hugohermogenes@gmail.com.

${ }^{3} \mathrm{PDIZ} / \mathrm{CCA} / \mathrm{UFPB}$ - Pesquisador do CNPq.

${ }^{4} \mathrm{PDIZ} / \mathrm{CCA} / \mathrm{UFPB}$ - Pesquisador do CNPq.

${ }^{5}$ Departamento de Zootecnia UFC/CCA.

${ }^{6}$ Departamento de Agronomia, UFCA, Campus Crato (CE).
} 


\section{INTRODUÇÃO}

A busca de alternativas alimentares que proporcionem o equilíbrio na disponibilidade nutritiva ao longo do ano, principalmente durante a época de menor ocorrência de precipitação pluviométrica, cuja escassez de alimentos promove limitações nutricionais aos rebanhos do semiárido brasileiro, é de vital importância para o sucesso da pecuária nesta região.

$\mathrm{O}$ cultivo de plantas adaptadas às condições do semiárido brasileiro pode manter o equilíbrio na oferta alimentar ao longo do ano, reduzindo a escassez de forragens no período de seca. Com isso, tornase necessário um aprofundamento nas pesquisas com espécies presentes no semiárido, notadamente quanto ao seu valor qualitativo e quantitativo, para que dessa maneira se consiga a sustentabilidade do meio rural (PEREIRA et al., 2012; SANTOS et al., 2010).

A parte aérea das euforbiáceas pode ser uma alternativa para aumentar a viabilidade econômica e a produtividade da pecuária dessa região, principalmente nas secas, devido ao seu valor nutritivo e aceitabilidade pelos rebanhos (FERREIRA et al., 2009). Assim, a pornunça (Manihot sp.) surge como uma das alternativas alimentares para a produção animal por apresentar valor nutritivo e palatabilidade, devendo ser cultivada na forma de lavoura xerófila. Suas raízes tuberosas com elevada capacidade de reserva em amido e água torna esta espécie persistente ao período seco.

O uso de adubações com esterco animal é um procedimento comumente adotado que visa suprir as necessidades de nutrientes, principalmente nitrogênio e fósforo, em áreas de agricultura familiar no semiárido brasileiro (MENEZES; SALCEDO, 2007). De forma geral, os solos desta região são deficitários em N e P, Logo, a produtividade sem reposição de nutrientes é baixa (MENEZES; SILVA, 2008; GALVÃO et al., 2008).

A composição química e mineral de uma forrageira é um dos mais importantes parâmetros utilizados para avaliar seu valor nutritivo (PARENTE et al., 2007), sendo que características próprias da espé- cie e estádio de desenvolvimento são fatores que alteram sua qualidade (MOREIRA FILHO et al., 2009). Contudo, o conhecimento desses aspectos qualitativos da pornunça é escasso, na região semiárida, particularmente em cultivos adubados com estercos animais.

Neste contexto, objetivou-se avaliar o efeito da adubação orgânica e de cortes sobre a composição química e a digestibilidade in vitro da matéria seca dos componentes estruturais da fitomassa aérea da pornunça no Curimataú paraibano.

\section{MATERIAL E MÉTODOS}

Este estudo foi conduzido na Fazenda Cumatí, localizada a $6^{\circ} 49^{\prime} 13^{\prime \prime}$ de latitude Sul e $36^{\circ} 21^{\prime} 38^{\prime \prime}$ de longitude Oeste, a $546 \mathrm{~m}$ de altitude, inserida no município de Cubatí, mesorregião da Borborema, e na microrregião do Seridó Oriental, conhecido como Curimataú paraibano. Apresenta clima Bsh (semiárido quente), segundo a classificação de Koppen, com chuvas de janeiro a abril, com precipitação e temperatura média anuais em torno de $400 \mathrm{~mm}$ e $26{ }^{\circ} \mathrm{C}$, respectivamente.

$\mathrm{Na}$ área experimental foram coletadas amostras de solo a duas profundidades $(0-20 \mathrm{~cm}$ e $20-40$ $\mathrm{cm})$ para análise química de fertilidade e caracterização física, com dez amostras simples para cada profundidade, originando uma amostra composta por profundidade.

Foram coletadas amostras dos estercos bovino e ovino e com as amostras dos solos foram conduzidas para processamento e análise conforme metodologia adotada pela EMBRAPA (2006) nos laboratórios de Química e Fertilidade do Solo e no de Física do Solo do Departamento de Solos e Engenharia Rural do Centro de Ciências Agrárias da Universidade Federal da Paraíba (UFPB).

De acordo com o resultado da análise (Tabela 1) foi recomendado o uso de $20 \mathrm{Mg} \mathrm{ha}^{-1}$ de esterco bovino e ovino. Não foi realizada correção e/ou adição de macro e/ou micronutrientes.

Tabela 1. Valores dos atributos químicos do solo e estercos aplicados na área experimental.

\begin{tabular}{cccccccccccc}
\hline \multirow{2}{*}{ Identificação } & $\mathrm{pH}$ & $\mathrm{P}$ & $\mathrm{K}^{+}$ & $\mathrm{Na}^{+}$ & $\mathrm{H}^{+}+\mathrm{Al}^{+3}$ & $\mathrm{Al}^{+3}$ & $\mathrm{Ca}^{+2}$ & $\mathrm{Mg}^{+2}$ & $\mathrm{SB}$ & $\mathrm{CTC}$ & $\mathrm{MO}$ \\
\cline { 2 - 10 } & $\begin{array}{c}\mathrm{H}_{2} \mathrm{O} \\
(1: 2,5)\end{array}$ & \multicolumn{2}{c}{$\mathrm{mg} / \mathrm{dm}^{3}$} & & & & $\mathrm{Cmolc} / \mathrm{dm}^{3}$ & & & $\mathrm{~g} / \mathrm{kg}^{-1}$ \\
\hline Solo $(0-20 \mathrm{~cm})$ & 6,46 & 16,11 & 54,04 & 0,1 & 1,32 & 0 & 2,1 & 0,35 & 2,67 & 3,99 & 3,19 \\
Solo $(20-40 \mathrm{~cm})$ & 6,22 & 10,59 & 51,55 & 0,1 & 0,83 & 0 & 1,8 & 0,15 & 2,15 & 2,98 & 2,57 \\
Esterco Bovino & 9,48 & 1013,6 & 3990 & 9,5 & 0 & 0 & 5,7 & 3,75 & 29,1 & 29,1 & 237,7 \\
Esterco Ovino & 8,91 & 1062,7 & 2343 & 5,6 & 0,17 & 0 & 7,8 & 10,1 & 29,4 & 29,6 & 290,3 \\
\hline
\end{tabular}

O solo apresentou uma distribuição granulométrica para as profundidades de $0-20 \mathrm{~cm}$ e $20-40$ $\mathrm{cm}$, respectivamente, de 615 e $559 \mathrm{~g} / \mathrm{kg}$ de areia grossa, 272 e $330 \mathrm{~g} / \mathrm{kg}$ de areia fina, 85 e $77 \mathrm{~g} / \mathrm{kg}$ de silte e 28 e $34 \mathrm{~g} / \mathrm{kg}$ de argila, sendo classificado como Neossolo Regolítico. (PARAÍBA, 2012). 
Durante o período experimental (abril de 2010 a abril de 2012) a precipitação total foi de 914 mm, temperatura máxima de $30,2{ }^{\circ} \mathrm{C}$, mínima de 22 ${ }^{\circ} \mathrm{C}$ e média de $26{ }^{\circ} \mathrm{C}$ no local do experimento.

As precipitações ao longo do período experimental (Tabela 2) concentraram-se nos meses de março a maio, sendo o período seco (sem chuva) de agosto a dezembro. É importante mencionar que em outubro de 2010 em dois dias choveu $120 \mathrm{~mm}$, precipitação atípica, pois nos últimos quinze anos o mês de outubro somou apenas $59 \mathrm{~mm}$ (AESA, 2012).

Tabela 2. Precipitação pluviométrica mensal (mm) ocorrida na área experimental, Fazenda Cumatí, entre abril de 2010 a abril de 2012

\begin{tabular}{|c|c|c|c|c|c|c|c|c|c|c|c|c|c|}
\hline \multirow[t]{2}{*}{ Ano } & \multicolumn{12}{|c|}{ Meses } & \multirow[t]{2}{*}{ Tota } \\
\hline & Jan. & Fev. & Mar. & Abr. & Mai. & Jun. & Jul. & Ago. & Set. & Out. & Nov. & Dez. & \\
\hline 2010 & - & - & - & 39 & 14 & 81 & 10 & 0 & 0 & 120 & 0 & 73 & 337 \\
\hline 2011 & 69 & 40 & 63 & 118 & 169 & 15 & 96 & 0 & 0 & 0 & 0 & 0 & 570 \\
\hline 2012 & 7 & 0 & 0 & 0 & - & - & - & - & - & - & - & - & 7 \\
\hline
\end{tabular}

Dados coletados no local.

A partir de agosto de 2011 até abril de 2012 praticamente não ocorreu eventos de chuva, caracterizando um longo período de seca (nove meses). Estes dados evidenciam alta variabilidade anual e mensal, típico do semiárido brasileiro.

O delineamento experimental foi em blocos ao acaso com quatro repetições em parcelas subdivididas, tendo a parcela principal dois estercos (bovino e ovino) e nas subparcelas quatro cortes. A unidade experimental foi formada por três fileiras de pornunça perfazendo nove plantas com espaçamento de 1,5 x 1,5 m (4.444 plantas ha $\left.{ }^{-1}\right)$, em parcelas de 5 x 5 m.

$\mathrm{O}$ plantio foi realizado com mudas provenientes do Viveiro Florestal do Instituto Nacional do Semiárido - INSA em 20 de março de 2010. Foram realizadas duas adubações orgânicas com intervalo de dez meses em maio de 2010 e março de 2011 na quantidade de $20 \mathrm{Mg} \mathrm{ha}^{-1}$. Os estercos bovino e ovino foram distribuídos em torno das plantas de pornunça. E as capinas manuais realizadas na medida do surgimento das ervas invasoras, sendo cinco em 2010, três em 2011 e nenhuma em 2012.

O período de abril de 2010 a fevereiro de 2011 foi destinado para o estabelecimento da cultura, sem realização de cortes, e no período de fevereiro de 2011 a abril de 2012 realizados quatro cortes sucessivos a $40 \mathrm{~cm}$ do solo em fevereiro, junho, outubro de 2011 e fevereiro de 2012.

A definição dos cortes decorreu em função do estádio fenológico das plantas, considerando adequado quando as mesmas estavam em pleno desenvolvimento, logo após a floração e antes da frutificação, tendo-se em média intervalo de cortes de 126 dias para o segundo, terceiro e quatro cortes.

Para a determinação da composição química e digestibilidade in vitro da MS foram cortadas nove plantas por parcela, ocorrendo a separação do material coletado em quatro componentes: limbos foliares; pecíolos; ramos (diâmetro menor ou igual a um centímetro); e completo (limbos foliares, pecíolos e ramos).

De cada componente amostrado foram sepa- rados $300 \mathrm{~g}$ em sacos de papel conduzidos ao Laboratório de Análise e Avaliação de Alimentos do Centro de Ciências Agrárias, Campus de Areia, da Universidade Federal da Paraíba - CCA/UFPB, sendo submetidas a pré-secagem em estufa de circulação forçada de ar a $55{ }^{\circ} \mathrm{C}$ até atingir peso constante para em seguida serem trituradas em moinho com peneira de malha de 1,0 $\mathrm{mm}$ e acondicionadas em recipientes fechados devidamente identificados para posteriores análises laboratoriais.

A determinação da matéria seca (MS), extrato etéreo (EE) e proteína bruta $(\mathrm{PB})$ ocorreu pelo método Kjedahl, e fibra em detergente neutro (FDN), fibra em detergente ácido (FDA), teores de lignina e hemicelulose pelo método de Van Soest (1994), descrito em Silva e Queiroz (2006).

A digestibilidade in vitro de matéria seca (DIVMS) foi determinada segundo a metodologia adaptada de Tilley e Terry (1963). A estimativa dos carboidratos totais (CHOT) e carboidratos não fibrosos $(\mathrm{CNF})$ seguiu a fórmula $\mathrm{CHOT}=100-(\% \mathrm{~PB}+$ $\% \mathrm{EE}+\% \mathrm{MM})$ e $\mathrm{CNF}=100-(\% \mathrm{FDN}+\% \mathrm{~PB}+\%$ $\mathrm{EE}+\% \mathrm{MM})$, respectivamente, segundo descrição encontrada em Berchielli et al. (2006).

Os dados das avaliações foram submetidos à análise de variância, avaliadas pelo teste Bartlett, quanto à homogeneidade e pelo teste KolmogorovSmirnov quanto à normalidade.

As variâncias das variáveis que se mostraram homogêneas tiveram os fatores em estudo avaliados pelo teste $\mathrm{F}$, caso contrário far-se-ia uso da transformação. Quando os resultados revelaram significância ao nível de $5 \%$ de probabilidade as médias foram comparadas pelo teste Tukey no nível de 5\% de probabilidade.

Os dados obtidos foram submetidos à análise de variância, empregando-se o programa de análise estatística SISVAR (FERREIRA, 2000) segundo o modelo matemático $\mathrm{Y}_{\mathrm{ijk}}=\mu+\mathrm{b}_{\mathrm{i}}+\mathrm{t}_{\mathrm{j}}+\mathrm{e}_{\mathrm{ij}}+\mathrm{c}_{\mathrm{k}}+\mathrm{e}_{\mathrm{ijk}}$, em que: $\mathrm{Y}_{\mathrm{ijk}}=$ variável independente; $\mu=$ média geral; $b_{i}=$ efeito do bloco $\mathrm{i} ; \mathrm{i}(\mathrm{i}=1,2,3,4) ; \mathrm{t}_{\mathrm{j}}=$ efeito do tratamento $\mathrm{j} ; \mathrm{j}(\mathrm{j}=1,2) ; \mathrm{e}_{\mathrm{ij}}=$ erro da parcela prin-

Revista Caatinga, Mossoró, v. 28, n. 3, p. 215 - 222, jul. - set., 2015 
cipal; $\mathrm{c}=$ efeito do corte $\mathrm{k} ;(\mathrm{k}=1,2,3,4) ; \mathrm{tc}_{\mathrm{jk}}=$ efeito de interação tratamento $\mathrm{x}$ corte; $\mathrm{e}_{\mathrm{ijk}}=$ erro experimental.

\section{RESULTADOS E DISCUSSÃO}

Os estercos bovino e ovino não afetaram os valores de MS, FDN, FDA, Hemicelulose e PB dos componentes estruturais (limbo foliar, pecíolo, ra- mos e completo) da pornunça (Tabelas $3,4,5,6$ e 7) e houve efeito $(p<0,05)$ do corte sobre a composição química dos componentes estruturais da mesma. De acordo com a análise química (Tabela 1), os estercos bovino e ovino apresentaram características semelhantes. Portanto, provavelmente foi o fator primordial que contribuiu para os componentes da pornunça, limbo foliar, pecíolo, ramos e parte completa não apresentarem diferenças significativas na composição química.

Tabela 3. Teores médios $(\mathrm{g} / \mathrm{kg})$ de matéria seca (MS) nos diferentes componentes estruturais da pornunça sob efeito de adubos orgânicos e cortes no Curimatau paraibano.

\begin{tabular}{|c|c|c|c|c|c|c|c|c|c|c|}
\hline \multicolumn{11}{|c|}{ MS (g/kg) } \\
\hline Estercos & \multicolumn{10}{|c|}{ Cortes } \\
\hline & $\mathrm{C} 1^{*}$ & $\mathrm{C} 2$ & C3 & $\mathrm{C} 4$ & MD & $\mathrm{C} 1$ & $\mathrm{C} 2$ & C3 & $\mathrm{C} 4$ & MD \\
\hline \multicolumn{6}{|c|}{ Limbo Foliar (g/kg) } & \multicolumn{5}{|c|}{ Pecíolo (g/kg) } \\
\hline Bovino & 357,5 & 355,0 & 337,5 & 337,5 & $346,9 \mathrm{~A}$ & 260,0 & 202,5 & 187,5 & 230,0 & $220,0 \mathrm{~A}$ \\
\hline Ovino & 337,5 & 297,5 & 305,0 & 335,0 & $318,8 \mathrm{~A}$ & 270,0 & 187,5 & 192,5 & 235,0 & $221,2 \mathrm{~A}$ \\
\hline Média & $347,5 \mathrm{a}$ & $326,3 \mathrm{a}$ & $321,3 a$ & $336,3 a$ & & $265,0 \mathrm{a}$ & $195,0 \mathrm{~b}$ & $190,0 \mathrm{~b}$ & $232,5 \mathrm{ab}$ & \\
\hline & C.V. $\cdot 1(\%)$ & ${ }^{1}=14,55$ & C.V. ${ }_{2}(9$ & )$^{2}=14,19$ & & C.V. ${ }_{1}($ & $=18,76$ & $\mathrm{C} . \mathrm{V} \cdot 2 \mathrm{C}$ & )$=14,81$ & \\
\hline \multicolumn{6}{|c|}{ Ramo $(\mathrm{g} / \mathrm{kg})$} & \multicolumn{5}{|c|}{ Completo $(\mathrm{g} / \mathrm{kg})$} \\
\hline Bovino & 347,5 & 240,0 & 370,0 & 272,5 & $307,5 \mathrm{~A}$ & 325,0 & 262,5 & 320,0 & 292,5 & $300,0 \mathrm{~A}$ \\
\hline Ovino & 320,0 & 220,0 & 275,0 & 262,5 & $269,4 \mathrm{~A}$ & 300,0 & 237,5 & 275,0 & 292,5 & $276,2 \mathrm{~A}$ \\
\hline \multirow[t]{2}{*}{ Média } & $333,8 \mathrm{a}$ & $230,0 \mathrm{~b}$ & $322,5 \mathrm{ab}$ & $267,5 \mathrm{ab}$ & & $312,5 \mathrm{a}$ & $250,0 \mathrm{~b}$ & $297,5 \mathrm{ab}$ & $292,5 \mathrm{ab}$ & \\
\hline & \multicolumn{2}{|c|}{ C.V. ${ }_{1}(\%)=20,81$} & \multicolumn{2}{|c|}{ C.V. $.2(\%)=25,13$} & & \multicolumn{2}{|c|}{ C. $V_{\cdot 1}(\%)=17,99$} & \multicolumn{2}{|c|}{ C.V. $\cdot 2(\%)=14,96$} & \\
\hline
\end{tabular}

${ }^{*} \mathrm{C} 1$ = Corte efetuado em fevereiro de 2011; C2 = Corte efetuado em junho 2011; C3 = Corte efetuado em outubro de 2011; $\mathrm{C} 4$ = Corte efetuado em fevereiro de 2012; e MD = Média.

Médias seguidas por letras iguais nas colunas e linhas não diferem a $5 \%$ de probabilidade pelo teste de Tukey.

${ }^{1}$ Coeficiente de variação dos tratamentos da parcela principal (Esterco bovino e ovino).

${ }^{2}$ Coeficiente de variação da subparcela (Efeito cortes).

Observa-se na Tabela 3 que os maiores valores de MS, de modo geral, ocorreram em todos os componentes estruturais da pornunça no corte 1 , provavelmente pelo maior período em dias ocorrido para efetuar o primeiro corte e pelo total de precipitação $(109 \mathrm{~mm})$ em todo o período de crescimento da pornunça. Já os menores valores de MS ocorreram no pecíolo, ramos e parte completa no segundo corte, provavelmente devido o período de crescimento da pornunça ter sido favorecida pelo maior precipitação, de $365 \mathrm{~mm}$ (Tabela 2).

O limbo foliar apresentou maiores valores de MS e o pecíolo os menores, o que é justificado, considerando a folha da pornunça apresentar adaptação a situações de déficit hídrico e o pecíolo parte mais turgido, mesmo sendo o responsável pela sustentabilidade do limbo foliar.

Os valores de MS do componente completo da pornunça encontrados neste trabalho são coerentes e semelhantes aos relatados por Vasconcelos et al. (2010) e Ferreira et al. (2009).

Os cortes influenciaram $(\mathrm{p}<0,05)$ os teores de FDN, FDA e Hemicelulose (Tabelas 4, 5 e 6) nos componentes limbo foliar, pecíolo e ramos e não significativo $(\mathrm{p}>0,05)$ para o componente completo.

Observou-se que os maiores valores de FDN,

FDA e Hemicelulose foram nos ramos do que nos limbos foliares e pecíolos da pornunça, provavelmente devido ao componente ramo conter mais fibras e tecidos de condução com parede secundária mais lignificada. De modo geral, o limbo foliar apresentou em todos os cortes efetuados os menores valores de FDN, FDA e Hemicelulose, o que caracteriza como o componente da pornunça com melhor composição química, o que é importante para a alimentação animal, pois quanto menor for o teor da parede celular melhor será a possibilidade de aproveitamento do limbo foliar ao serem consumidos pelos animais. No que toca a FDN, FDA e Hemicelulose do componente completo (limbo foliar + pecíolo + ramos) da pornunça estas não foram influenciadas pelos cortes, mostrando que a pornunça pode ser manejada com intervalos de cortes de 126 dias, sem provocar alteração na parede celular, nas condições em que o trabalho foi realizado. 
F. H. H. DE ALENCAR et al.

Tabela 4. Teores médios ( $\mathrm{g} / \mathrm{kg}$ ) de fibra em detergente neutro (FDN) nos diferentes componentes estruturais da parte aérea da pornunça sob efeito de adubos orgânicos e cortes no Curimatau paraibano.

\begin{tabular}{|c|c|c|c|c|c|c|c|c|c|c|}
\hline \multicolumn{11}{|c|}{ FDN (g/kg) } \\
\hline \multirow{3}{*}{ Estercos } & \multicolumn{10}{|c|}{ Cortes } \\
\hline & $\mathrm{C} 1^{*}$ & C 2 & C 3 & $\mathrm{C} 4$ & MD & $\mathrm{C} 1$ & C 2 & C 3 & $\mathrm{C} 4$ & MD \\
\hline & \multicolumn{4}{|c|}{ Limbo Foliar (g/kg) } & \multicolumn{6}{|c|}{ Pecíolo (g/kg) } \\
\hline Bovino & 382,5 & 355,0 & 335,0 & 370,0 & $360,6 \mathrm{~A}$ & 505,0 & 515,0 & 472,5 & 437,5 & $482,5 \mathrm{~A}$ \\
\hline Ovino & 420,0 & 365,0 & 315,0 & 387,5 & $371,9 \mathrm{~A}$ & 472,5 & 542,5 & 477,5 & 467,5 & $490,0 \mathrm{~A}$ \\
\hline \multirow[t]{3}{*}{ Média } & $401,2 \mathrm{a}$ & $360,0 \mathrm{ab}$ & $325,0 \mathrm{~b}$ & $378,7 \mathrm{ab}$ & & $488,7 \mathrm{ab}$ & $528,7 \mathrm{a}$ & $475,0 \mathrm{~b}$ & $452,5 b$ & \\
\hline & C.V. $.1(\%)$ & $=11,08$ & C.V. $.2 \%$ & $2=11,35$ & & C.V. .1 & $=3,31$ & C.V.2( & $=7,04$ & \\
\hline & \multicolumn{4}{|c|}{ Ramo $(\mathrm{g} / \mathrm{kg})$} & \multicolumn{6}{|c|}{ Completa $(\mathrm{g} / \mathrm{kg})$} \\
\hline Bovino & 560,0 & 597,5 & 605,0 & 515,0 & $569,4 \mathrm{~A}$ & 422,5 & 447,5 & 455,0 & 405,0 & $432,5 \mathrm{~A}$ \\
\hline Ovino & 565,0 & 630,0 & 582,5 & 505,0 & $570,6 \mathrm{~A}$ & 437,5 & 445,0 & 447,5 & 425,5 & $434,4 \mathrm{~A}$ \\
\hline \multirow[t]{2}{*}{ Média } & $562,5 \mathrm{ab}$ & $613,7 \mathrm{a}$ & $593,7 \mathrm{a}$ & $510,0 \mathrm{~b}$ & & $430,0 \mathrm{a}$ & $446,2 \mathrm{a}$ & $441,2 \mathrm{a}$ & $416,2 \mathrm{a}$ & \\
\hline & \multicolumn{2}{|c|}{ C.V. $(\%)=5,67$} & \multicolumn{2}{|c|}{ C.V. $.2(\%)=6,71$} & & \multicolumn{2}{|c|}{ C.V. $\cdot 1 \%)=5,93$} & \multicolumn{2}{|c|}{ C.V. ${ }_{2}(\%)=7,97$} & \\
\hline
\end{tabular}

${ }^{*} \mathrm{C} 1$ = Corte efetuado em fevereiro de 2011; C2 = Corte efetuado em junho 2011; C3 = Corte efetuado em outubro de 2011; $\mathrm{C} 4$ = Corte efetuado em fevereiro de 2012; e MD = Média.

Médias seguidas por letras iguais nas colunas e linhas não diferem a 5\% de probabilidade pelo teste de Tukey.

${ }^{1}$ Coeficiente de variação dos tratamentos da parcela principal (Esterco bovino e ovino).

${ }^{2}$ Coeficiente de variação da subparcela (Efeito cortes).

Tabela 5. Teores médios $(\mathrm{g} / \mathrm{kg}$ ) de fibra em detergente ácido (FDA) nos diferentes componentes estruturais da pornunça sob efeito de adubos orgânicos e cortes no Curimatau paraibano.

\begin{tabular}{|c|c|c|c|c|c|c|c|c|c|c|}
\hline \multicolumn{11}{|c|}{ FDA $(\mathrm{g} / \mathrm{kg})$} \\
\hline \multirow[t]{3}{*}{ Estercos } & \multicolumn{10}{|c|}{ Cortes } \\
\hline & $\mathrm{C} 1^{*}$ & $\mathrm{C} 2$ & C3 & C4 & MD & $\mathrm{C} 1$ & $\mathrm{C} 2$ & C3 & $\mathrm{C} 4$ & MD \\
\hline & \multicolumn{4}{|c|}{ Limbo Foliar (g/kg) } & \multicolumn{6}{|c|}{ Pecíolo (g/kg) } \\
\hline Bovino & 332,5 & 330,0 & 300,0 & 340,0 & $325,6 \mathrm{~A}$ & 425,0 & 457,5 & 410,0 & 375,0 & $416,9 \mathrm{~A}$ \\
\hline Ovino & 350,0 & 340,0 & 282,5 & 352,5 & $331,2 \mathrm{~A}$ & 427,5 & 472,5 & 420,0 & 400,0 & $430,0 \mathrm{~A}$ \\
\hline \multirow{3}{*}{ Média } & $341,2 \mathrm{ab}$ & $335,0 \mathrm{ab}$ & $291,2 \mathrm{~b}$ & $346,2 \mathrm{a}$ & & $426,2 b$ & $465,0 \mathrm{a}$ & $415,0 \mathrm{bc}$ & $387,5 \mathrm{c}$ & \\
\hline & C.V. $\cdot 1(\%)^{1}$ & $=11,10$ & C.V. $.2(\%$ & $=11,39$ & & C.V. $\cdot 1(9$ & $=7,23$ & C.V. $.2(\%$ & $=5,69$ & \\
\hline & \multicolumn{4}{|c|}{ Ramo $(\mathrm{g} / \mathrm{kg})$} & \multicolumn{6}{|c|}{ Completa $(\mathrm{g} / \mathrm{kg})$} \\
\hline Bovino & 440,0 & 527,5 & 505,0 & 397,5 & $467,5 \mathrm{~A}$ & 347,5 & 372,5 & 390,0 & 340,0 & $362,5 \mathrm{~A}$ \\
\hline Ovino & 452,5 & 560,0 & 497,5 & 455,0 & $478,5 \mathrm{~A}$ & 367,5 & 380,0 & 370,0 & 365,0 & $371,9 \mathrm{~A}$ \\
\hline \multirow{2}{*}{ Média } & $446,2 b$ & $543,7 \mathrm{a}$ & $501,2 \mathrm{a}$ & $401,2 \mathrm{~b}$ & & $357,5 \mathrm{a}$ & $376,2 \mathrm{a}$ & $382,5 \mathrm{a}$ & $352,5 \mathrm{a}$ & \\
\hline & \multicolumn{2}{|c|}{$\begin{array}{c}440,20 \\
\text { C.V. }(\%)=6,50\end{array}$} & \multicolumn{2}{|c|}{ C.V. $2(\%)=6,98$} & & \multicolumn{2}{|c|}{ C.V. $\cdot 1(\%)=11,10$} & \multicolumn{2}{|c|}{ C.V. ${ }_{2}(\%)=8,15$} & \\
\hline
\end{tabular}

${ }^{*} \mathrm{C} 1=$ Corte efetuado em fevereiro de 2011; C2 = Corte efetuado em junho 2011; C3 = Corte efetuado em outubro de 2011; C4 = Corte efetuado em fevereiro de 2012; e MD = Média.

Médias seguidas por letras iguais nas colunas e nas linhas não diferem a 5\% de probabilidade pelo teste de Tukey.

${ }^{1}$ Coeficiente de variação dos tratamentos da parcela principal (Esterco bovino e ovino).

${ }^{2}$ Coeficiente de variação da subparcela (Efeito cortes).

Tabela 6. Teores médios $(\mathrm{g} / \mathrm{kg})$ de hemicelulose $(\mathrm{HC})$ nos diferentes componentes estruturais da pornunça sob efeito de adubos orgânicos e cortes no Curimatau paraibano.

\begin{tabular}{|c|c|c|c|c|c|c|c|c|c|c|}
\hline \multicolumn{11}{|c|}{$\mathrm{HC}(\mathrm{g} / \mathrm{kg})$} \\
\hline \multirow[t]{3}{*}{ Estercos } & \multicolumn{10}{|c|}{ Cortes } \\
\hline & $\mathrm{C} 1 *$ & $\mathrm{C} 2$ & $\mathrm{C} 3$ & $\mathrm{C} 4$ & $\mathrm{MD}$ & $\mathrm{C} 1$ & $\mathrm{C} 2$ & $\mathrm{C} 3$ & $\mathrm{C} 4$ & MD \\
\hline & \multicolumn{4}{|c|}{ Limbo Foliar (g/kg) } & \multicolumn{6}{|c|}{ Pecíolo (g/kg) } \\
\hline Bovino & 50,0 & 25,0 & 32,5 & 32,5 & $35,0 \mathrm{~A}$ & 80,0 & 57,5 & 65,0 & 65,0 & $66,9 \mathrm{~A}$ \\
\hline Ovino & 47,5 & 27,5 & 35,0 & 32,5 & $35,6 \mathrm{~A}$ & 75,0 & 70,0 & 60,0 & 67,5 & $68,1 \mathrm{~A}$ \\
\hline \multirow[t]{3}{*}{ Média } & $48,7 \mathrm{a}$ & $26,2 b$ & $33,7 b$ & $32,5 \mathrm{~b}$ & & $77,5 \mathrm{a}$ & $63,7 \mathrm{~b}$ & $62,5 b$ & $66,2 \mathrm{ab}$ & \\
\hline & C.V. $\cdot 1$ & $=25,03$ & C.V. $\cdot 2\left({ }^{\circ}\right.$ & $=24,12$ & & C.V. $\cdot{ }_{1}\left({ }^{\circ}\right.$ & $=17,89$ & C. $V_{\cdot 2}($ & $=13,12$ & \\
\hline & \multicolumn{4}{|c|}{ Ramo $(\mathrm{g} / \mathrm{kg})$} & \multicolumn{6}{|c|}{ Completa $(\mathrm{g} / \mathrm{kg})$} \\
\hline Bovino & 120,0 & 65,0 & 102,5 & 117,5 & $101,2 \mathrm{~A}$ & 75,0 & 77,5 & 65,0 & 62,5 & $70,0 \mathrm{~A}$ \\
\hline Ovino & 117,5 & 72,5 & 82,5 & 100,0 & $93,1 \mathrm{~A}$ & 72,5 & 65,0 & 57,5 & 62,5 & $64,4 \mathrm{~A}$ \\
\hline \multirow[t]{2}{*}{ Média } & $118,7 \mathrm{a}$ & $68,7 \mathrm{c}$ & $92,5 b$ & $108,7 \mathrm{ab}$ & & $73,7 \mathrm{a}$ & $71,2 \mathrm{a}$ & $61,2 \mathrm{a}$ & $62,5 \mathrm{a}$ & \\
\hline & \multicolumn{2}{|c|}{ C. $V_{\cdot 1}(\%)=12,02$} & \multicolumn{2}{|c|}{ C.V. $.2(\%)=15,68$} & & \multicolumn{2}{|c|}{ C.V. $\cdot 1(\%)=28,62$} & \multicolumn{2}{|c|}{ C.V $._{2}(\%)=22,89$} & \\
\hline
\end{tabular}

${ }^{*} \mathrm{C} 1$ = Corte efetuado em fevereiro de 2011; C2 = Corte efetuado em junho 2011; C3 = Corte efetuado em outubro de 2011; C4 = Corte efetuado em fevereiro de 2012; e MD = Média.

Médias seguidas por letras iguais nas colunas e linhas não diferem a $5 \%$ de probabilidade pelo teste de Tukey.

${ }^{1}$ Coeficiente de variação dos tratamentos da parcela principal (Esterco bovino e ovino).

${ }^{2}$ Coeficiente de variação da subparcela (Efeito cortes). 
Quanto aos valores médios de PB (Tabela 7) houveram diferenças $(p<0,05)$ em todos os componentes (limbo foliar, pecíolo, ramos e completo) da pornunça quando submetidas aos cortes, com os maiores valores de PB dos componentes do segundo corte, provavelmente influenciado pela melhor condição de precipitação ocorrida $(365 \mathrm{~mm})$. Já os menores valores de $\mathrm{PB}$ ocorreram nos componentes no quatro corte, com apenas $7 \mathrm{~mm}$ de precipitação durante o período de rebrota.
Considerando a quantidade de PB apresentada pela pornunça, componente completo, independente do corte, pode-se afirmar que a parte aérea da pornunça representa uma forrageira de excelente valor proteico. Os valores observados na Tabela 7 para componente completo da pornunça são semelhantes aos encontrados por (VASCONCELOS et al., 2010 e VOLTOLINI et al., 2010), de $139,1 \mathrm{~g} / \mathrm{kg}$ e $140,0 \mathrm{~g} / \mathrm{kg}$, respectivamente, e inferiores ao relatado por (FERREIRA et al., 2009), de 256,0 g/ $/ \mathrm{kg}$.

Tabela 7. Teores médios $(\mathrm{g} / \mathrm{kg})$ de proteína bruta $(\mathrm{PB})$ nos diferentes componentes estruturais da pornunça sob efeito de adubos orgânicos e cortes no Curimatau paraibano.

\begin{tabular}{|c|c|c|c|c|c|c|c|c|c|c|}
\hline \multicolumn{11}{|c|}{ PB (g/kg) } \\
\hline \multirow[t]{3}{*}{ Estercos } & \multicolumn{10}{|c|}{ Cortes } \\
\hline & $\mathrm{C} 1 *$ & $\mathrm{C} 2$ & C3 & $\mathrm{C} 4$ & MD & $\mathrm{C} 1$ & $\mathrm{C} 2$ & C3 & $\mathrm{C} 4$ & MD \\
\hline & \multicolumn{4}{|c|}{ Limbo Foliar (g/kg) } & \multicolumn{6}{|c|}{ Pecíolo (g/kg) } \\
\hline Bovino & 215,0 & 240,0 & 225,0 & 167,5 & $211,9 \mathrm{~A}$ & 60,0 & 72,5 & 65,0 & 47,5 & $61,2 \mathrm{~A}$ \\
\hline Ovino & 232,5 & 290,0 & 245,0 & 180,0 & $236,9 \mathrm{~A}$ & 57,5 & 65,0 & 67,5 & 50,0 & $60,0 \mathrm{~A}$ \\
\hline \multirow[t]{3}{*}{ Média } & $223,7 \mathrm{ab}$ & $265,0 \mathrm{a}$ & $235,0 \mathrm{a}$ & $173,7 \mathrm{~b}$ & & $58,7 \mathrm{ab}$ & $68,7 \mathrm{a}$ & $66,2 \mathrm{a}$ & $48,7 \mathrm{~b}$ & \\
\hline & C.V. ${ }_{1}(\%)$ & $=21,95$ & C.V.2 ( & $=16,58$ & & C.V. $\cdot 1$ & $=7,53$ & C.V. $\cdot 2(\%$ & $=14,93$ & \\
\hline & \multicolumn{4}{|c|}{ Ramo $(\mathrm{g} / \mathrm{kg})$} & \multicolumn{6}{|c|}{ Completa $(\mathrm{g} / \mathrm{kg})$} \\
\hline Bovino & 52,5 & 75,0 & 42,5 & 45,0 & $53,7 \mathrm{~A}$ & 147,5 & 202,5 & 135,0 & 115,0 & $150,0 \mathrm{~A}$ \\
\hline Ovino & 62,5 & 72,5 & 52,5 & 40,0 & $56,9 \mathrm{~A}$ & 152,5 & 205,0 & 142,5 & 117,5 & $154,4 \mathrm{~A}$ \\
\hline \multirow[t]{2}{*}{ Média } & $57,5 \mathrm{ab}$ & $73,7 \mathrm{a}$ & $47,5 b$ & $42,5 b$ & & $150,0 \mathrm{~b}$ & $203,7 \mathrm{a}$ & $138,7 \mathrm{bc}$ & $116,2 \mathrm{c}$ & \\
\hline & \multicolumn{2}{|c|}{ C.V. $\cdot 1(\%)=28,76$} & \multicolumn{2}{|c|}{ C.V. ${ }_{2}(\%)=21,86$} & & \multicolumn{2}{|c|}{ C.V. ${ }_{1}(\%)=11,75$} & \multicolumn{2}{|c|}{ C.V. ${ }_{2}(\%)=10,51$} & \\
\hline
\end{tabular}

${ }^{*} \mathrm{C} 1$ = Corte efetuado em fevereiro de 2011; C2 = Corte efetuado em junho 2011; C3 = Corte efetuado em outubro de 2011; $\mathrm{C} 4$ = Corte efetuado em fevereiro de 2012; e MD = Média.

Médias seguidas por letras iguais nas colunas e linhas não diferem a $5 \%$ de probabilidade pelo teste de Tukey.

${ }^{1}$ Coeficiente de variação dos tratamentos da parcela principal (Esterco bovino e ovino).

${ }^{2}$ Coeficiente de variação da subparcela (Efeito cortes).

Os valores de extrato etéreo, lignina, carboidratos não fibrosos, carboidratos totais e da digestibilidade in vitro da matéria seca da parte aérea da pornunça foram analisados como componentes completos (limbo foliar + pecíolo + ramo) (Tabela 8$)$. Não houve influência $(p>0,05)$ do esterco bovino e ovino para os valores de EE, LIG, CNF, CHOT e DIVMS do componente completo da pornunça e significativo $(\mathrm{p}<0,05)$ para LIG, CNF, CHOT e DIVMS.

Os cortes efetuados na pornunça não afetaram o teor de estrato etéreo, demonstrando que o esterco bovino e ovino e a maior ou menor quantidade de água (precipitação ocorrida) que foi disponibilizada à pornunça não influenciaram no valor do EE e os valores observados são compatíveis aos encontrados nas plantas forrageiras (MOREIRA FILHO et al., 2009).

Os menores valores de lignina foram observados na pornunça nos cortes 1 e 4 , os quais foram diferentes dos cortes 2 e 3 . Considerando que o corte 1 da pornunça ocorreu em fevereiro de 2011, com mais de 300 dias após plantio, com apenas $109 \mathrm{~mm}$ de precipitação, durante todo o período de crescimento da pornunça, e o corte 4 foi com 126 dias de rebrota e ocorreu apenas $7 \mathrm{~mm}$ de precipitação provavelmente a pornunça nos dois períodos de avaliação apresentaram menor crescimento, influenciando em menores valores de lignina. Por outro lado, esses cortes também apresentaram menores valores de FDN e FDA (Tabelas 4 e 5).

Para carboidratos não fibrosos o componente completo apresentou efeito significativo $(\mathrm{P}<0,05)$, com o menor valor de $274,8 \mathrm{~g} / \mathrm{kg}$, observado no corte dois. Quanto aos carboidratos totais ocorreu efeito $(\mathrm{P}<0,05)$ no corte dois, comparados aos cortes três e quatro, e não efeito em relação ao corte um.

Os maiores teores de carboidrato totais e não fibrosos da parte aérea da pornunça nos cortes três e quatro podem ser explicados pelo aumento dos valores de FDN e FDA destes respectivos cortes (Tabelas 4 e 5), os quais foram influenciados pela menor precipitação ocorrida de $96 \mathrm{~mm}$ e $7 \mathrm{~mm}$, respectivamente.

Houve efeito $(\mathrm{P}<0,05)$ para digestibilidade in vitro da MS da pornunça nos diferentes cortes, onde no primeiro corte o componente completo apresentou maior digestibilidade em relação aos demais cortes, o que pode ser explicado pelo menor teor de lignina apresentado pelo componente neste corte (Tabela 8). Voltolini et al. (2010) e Ferreira et al. (2009) encontraram valores de DIVMS de 490,0 e $493,2 \mathrm{~g} / \mathrm{kg}$, valores menores do que os encontrados neste trabalho. 
Tabela 8. Teores médios ( $\mathrm{g} / \mathrm{kg}$ ) do extrato etéreo (EE), lignina (LIG), carboidratos não fibrosos (CNF), carboidratos totais (CHOT) e da digestibilidade in vitro da matéria seca (DIVMS) do componente completo da parte aérea da pornunça sob efeito de esterco e cortes Curimatau paraibano.

\begin{tabular}{|c|c|c|c|c|c|c|c|c|c|c|}
\hline \multirow{2}{*}{ Esterco } & \multicolumn{10}{|c|}{ Cortes } \\
\hline & $\mathrm{C} 1 *$ & $\mathrm{C} 2$ & $\mathrm{C} 3$ & $\mathrm{C} 4$ & MD & $\mathrm{C} 1$ & $\mathrm{C} 2$ & $\mathrm{C} 3$ & $\mathrm{C} 4$ & MD \\
\hline & \multicolumn{4}{|c|}{$\mathrm{EE}(\mathrm{g} / \mathrm{kg})$} & \multicolumn{6}{|c|}{ LIG $(\mathrm{g} / \mathrm{kg})$} \\
\hline Bovino & 41,0 & 28,0 & 36,0 & 49,5 & $38,6 \mathrm{~A}$ & 213,8 & 254,4 & 261,1 & 205,9 & $233,8 \mathrm{~A}$ \\
\hline Ovino & 42,9 & 30,6 & 41,8 & 47,7 & $40,8 \mathrm{~A}$ & 220,1 & 259,1 & 263,8 & 218,7 & $240,4 \mathrm{~A}$ \\
\hline \multirow{3}{*}{ Média } & $42,0 \mathrm{a}$ & $29,3 \mathrm{a}$ & $38,9 \mathrm{a}$ & $48,6 \mathrm{a}$ & & $217,0 \mathrm{~b}$ & $256,8 \mathrm{a}$ & $262,5 \mathrm{a}$ & $212,3 b$ & \\
\hline & C.V. ${ }_{1}(\%)$ & ${ }^{1}=23,63$ & C. $V_{.2}(\%$ & $2^{2}=35,75$ & & C.V.$_{\cdot 1}($ & $=8,29$ & C..$_{.2}\left({ }^{0}\right.$ & $=7,65$ & \\
\hline & \multicolumn{4}{|c|}{$\mathrm{CNF}(\mathrm{g} / \mathrm{kg})$} & \multicolumn{6}{|c|}{ CHOT $(\mathrm{g} / \mathrm{kg})$} \\
\hline Bovino & 314,4 & 270,6 & 308,1 & 350,1 & $310,8 \mathrm{~A}$ & 737,3 & 717,4 & 762,1 & 754,0 & $742,7 \mathrm{~A}$ \\
\hline Ovino & 286,9 & 278,9 & 333,1 & 332,9 & $308,0 \mathrm{~A}$ & 732,0 & 717,4 & 762,4 & 758,7 & $740,4 \mathrm{~A}$ \\
\hline \multirow[t]{4}{*}{ Média } & $300,7 \mathrm{ab}$ & $274,8 b$ & $320,6 a$ & $341,5 \mathrm{a}$ & & $734,7 \mathrm{bc}$ & $717,4 \mathrm{c}$ & $762,3 a$ & $756 \mathrm{ab}$ & \\
\hline & \multicolumn{4}{|c|}{ C.V. $.1 \%)=4,83$} & & C. $\mathrm{V}_{\cdot 1}(\mathrm{C}$ & $=2,41$ & C.V.2 $(\%)$ & 2,88 & \\
\hline & \multicolumn{10}{|c|}{ DIVMS $(\mathrm{g} / \mathrm{kg})$} \\
\hline & \multicolumn{2}{|r|}{$\mathrm{C} 1$} & \multicolumn{2}{|c|}{$\mathrm{C} 2$} & \multicolumn{2}{|c|}{ C3 } & \multicolumn{2}{|c|}{$\mathrm{C} 4$} & \multicolumn{2}{|c|}{$\mathrm{MD}$} \\
\hline Bovino & \multicolumn{2}{|c|}{582,5} & \multicolumn{2}{|c|}{518,3} & \multicolumn{2}{|c|}{527,5} & \multicolumn{2}{|c|}{512,3} & \multicolumn{2}{|c|}{$535,2 \mathrm{~A}$} \\
\hline Ovino & \multicolumn{2}{|c|}{625,7} & \multicolumn{2}{|c|}{492,6} & & & \multicolumn{2}{|c|}{481,2} & \multicolumn{2}{|c|}{$525,2 \mathrm{~A}$} \\
\hline \multirow[t]{2}{*}{ Média } & \multirow{2}{*}{\multicolumn{4}{|c|}{$\begin{array}{c}60,4 \mathrm{la} \\
\mathrm{C} . \mathrm{V} \cdot \mathrm{l}(\%)=5,71 \\
\end{array}$}} & & & \multicolumn{2}{|c|}{$49,68 \mathrm{~b}$} & & \\
\hline & & & & & & C.V.V.2 $(\%$ & $=9,85$ & & & \\
\hline \multicolumn{11}{|c|}{$\begin{array}{l}{ }^{*} \mathrm{C} 1=\text { Corte efetuado em fevereiro de } 2011 ; \mathrm{C} 2=\text { Corte efetuado em junho } 2011 ; \mathrm{C} 3=\text { Corte efetuado em outubro de } 2011 ; \\
\mathrm{C} 4=\text { Corte efetuado em fevereiro de } 2012 ; \mathrm{e} \mathrm{MD}=\text { Média. } \\
\text { Médias seguidas de letras iguais nas colunas e linhas de cada variável não diferem a } 5 \% \text { de probabilidade pelo teste de } \\
\text { Tukey. }\end{array}$} \\
\hline
\end{tabular}

\section{CONCLUSÕES}

A composição química da pornunça dos componentes estruturais, limbo foliar, pecíolo, ramo e completo (limbo foliar + pecíolo + ramo) não foi influenciada pela adubação orgânica com esterco bovino e ovino nas condições ambientais onde o experimento foi realizado.

Os diferentes cortes realizados na pornunça afetaram a composição química dos componentes estruturais (limbo foliar, pecíolo, ramos e completo) e a digestibilidade in vitro da MS da parte aérea da pornunça.

A pornunça deve ser considerada como alternativa alimentar para os animais em função dos valores da composição química apresentados neste estudo, sendo o limbo foliar o componente com melhores valores na composição química.

\section{REFERÊNCIAS}

AESA. Agência Executiva de Gestão de Águas do Estado da Paraíba. Disponível em: http:// www.aesa.pb.gov.br. Acesso em 29 out. 2012.

BERCHIELLI, T. T.; GARCIA, A. V.; OLIVEIRA, S. G. Principais técnicas de avaliação em estudo de nutrição. In: BERCHIELLI, T. T.; PIRES, A. V.; OLIVEIRA, S. G. (Ed). Nutrição de Ruminantes. Jaboticabal, Funep, 2006. p. 397-418.

EMBRAPA - Sistema brasileiro de classificação de solos. SANTOS, H. G. et al. 2 ed. Rio de Janeiro: EMBRAPA Solos, 2006. 306 p.

FERREIRA, A. L. et al. Produção e valor nutritivo da parte aérea da mandioca, maniçoba e pornunça. Revista Brasileira de Saúde e Produção Animal, Salvador, v. 10, n. 1, p. 129-136, 2009.

FERREIRA, D. F. Manual do sistema Sisvar para análises estatísticas. Lavras, Universidade Federal de Lavras, 2000. 66 p.

FRANÇA, A. A. et al. Anatomia e cinética de degradação do feno de Manihot glaziovii. Acta Scientiarum. Animal Sciences, Maringá, v. 32, n. 2, p. 131 $-138,2010$.

GALVÃO, S. R. S.; SALCEDO, I. H.; OLIVEIRA, F. F. Acumulação de nutrientes em solos arenosos adubados com esterco bovino. Pesquisa Agropecuária Brasileira, Brasília, v. 43, n. 1, p. 99-105, 2008.

MENEZES, R. S. C.; SALCEDO. I. H. Mineralização de $\mathrm{N}$ após incorporação de adubos orgânicos em um Neossolo Regolítico cultivado com milho. Revista Brasileira de Engenharia Agrícola e Ambiental, Campina Grande, v. 11, p. 361-367, 2007.

MENEZES, R. S. C.; SILVA, T. O. Mudanças na fertilidade de um neossolo regolítico após seis anos de adubação orgânica. Revista Brasileira Engenharia Agrícola e Ambiental, Campina Grande, v. 12, n. 3, p. 251-257, 2008. 
MOREIRA FILHO, E. C. et al. Composição química de maniçoba submetida a diferentes manejos de solo, densidades de plantio e alturas de corte. Revista Caatinga, Mossoró, v. 22, n. 2, p. 187-194, 2009.

PARAÍBA, G. E.; SECTMA; AESA. Caracterização do Solo. Classes de Solos. Solos do Estado da Paraíba. Disponível em: <http:// www.aesa.pb.gov.br/perh/relatorio_final/Capitulo\% 202/pdf $/ 2.11 \% 20-\% 20$ CaracSolo.pdf $>$. Acesso em: 13 de mai. 2012.

PARENTE, H. N. et al. Influência da adubação nitrogenada sobre o crescimento inicial e composição química e mineral da maniçoba (Manihot sp.). Revista Científica da Produção Animal, Areia, v. 9, n. 2, p. 102-110, 2007.

PEREIRA, V. L. A. et al. Valor nutritivo e consumo voluntário do feno de faveleira fornecido a ovinos no semiárido pernambucano. Revista Caatinga, Mossoró, v. 25, n. 3, p. 96-101, 2012.

SANTOS, M. V. F. et al. Potential of caatinga forage plants in ruminant feeding. Revista Brasileira de Zootecnia, Viçosa, v. 39, p. 204-215, 2010. (Suplemento especial).

SILVA, D. J.; QUEIROZ, A. C. Análise de alimentos: métodos químicos e biológicos. Viçosa: UFV, 2006. $235 \mathrm{p}$.

TILLEY, J. M. A.; TERRY, R. A. A two-stage technique for the in vitro digestion of forage crops. Journal of British Grassland Society, Oxford, v. 18, n. 2, p. 104-111, 1963.

VAN SOEST, P. J. Nutritional ecology of the ruminant. 2. ed. Ithaca: Cornell University, 1994. 476 p.

VASCONCELOS, W. A. et al. Morfometria, produção e composição bromatológica da Maniçoba e Pornunça em resposta a diferentes fontes de adubação. Revista Trópica - Ciências Agrárias e Biológicas, Chapadinha, v. 4, n. 2, p. 36 - 43, 2010.

VOLTOLINI, T. V. et al. Alternativas alimentares e sistemas de produção animal para o semiárido brasileiro. In: SÁ, I. B.; SILVA, P. C. G. (Eds.). Semiárido brasileiro: pesquisa, desenvolvimento e inovação. EMBRAPA SEMIÁRIDO, Petrolina, p. 199242, 2010. 